\title{
Bi-lamellar lower eyelid reconstruction with superficial temporal artery island flap and hard palate muco-periosteal free graft
}

\author{
V. Jacob, N. J. Mokal, S. N. Deshpande \\ Department of Plastic Surgery, Grant Medical College \& G. T. Hospital, Mumbai
}

Address for correspondence: Vinay Jacob, Department of Plastic Surgery, Ward 4 G. T. Hospital, L.T. Marg, Mumbai -400001. E-mail: drvinayjacob@yahoo.co.in

\begin{abstract}
Three cases of single stage, bi-lamellar reconstruction of full-thickness, horizontal, lateral threequarter lower eyelid defects using pedicled island flaps of adjacent vascular territories and hard palate muco-periosteal graft are being presented.

All cases were done for Basal Cell Carcinoma of the region. While the island flaps allowed for a simple, single stage reconstruction of the external lamella, the hard palate muco-periosteal graft, by virtue of its inherent resilience and a rich glandular component, took well and provided for a good functional and aesthetic result.

The follow-up ranged from 6 to 40 months and the final result has been oncologically, functionally and aesthetically satisfactory.
\end{abstract}

\section{KEY WORDS}

Island superficial temporal artery flap, Hard palatal muco-periosteal graft, Bi-lamellar lower eyelid defect reconstruction, Full thickness lower eyelid defect reconstruction

\section{INTRODUCTION}

rimary aim of reconstruction of full thickness defects of the eyelids following tumor ablation is the reconstitution of the tarsal plate as a supportive layer of the lid, and replacement of the conjunctival lining with a similar secretory tissue.

There are only a few reports on the use of the hard palatal muco-periosteum as a tarso-conjunctival substitute. It has been used for a single stage reconstruction of the lower eyelid bi-lamella along with an island pedicled flap of the anterior branch of the superficial temporal artery.

Three patients with horizontal, three-quarter defects of the lower eyelid (tumor resection) have been treated using this technique. The oncological, functional and aesthetic results have been excellent in each of the three cases.

This technique is ideal for central, off-central and lateral losses involving up to $75 \%$ of the width of the lower eyelid. It is a better alternative to the Hughes (1945), Mustarde (1981), Tenzel and Stewart (1978) and the McGregor (1973) techniques that have been in use earlier for similar 
Jacob V, et al.

reconstructions.

\section{MATERIALS AND METHODS}

Apart from the oncological evaluation, the following parameters were assessed: location, eyelid closure, epiphora, length of the palpebral rim, the palpebral fissure, levator function, an aesthetic balance of the eyelids, and donor site morbidity.

Tumoral ablation defects on the average measured 2.4 centimeters horizontally and 1.6 centimeters vertically. They involved three-quarter to a near total loss of the lower eyelid. Including - (1) skin (2) lower ocular conjunctiva and (3) tarsal plate.

An island flap, based on the anterior branch of the superficial temporal artery, was raised for the external lamella eyelid reconstruction of each of the three patients.

The skin island was elevated from the skin at the upper lateral frontal area, just anterior to the hairline, leaving minimal scarring and maintaining a long vascular pedicle.

The arterial pedicle was appropriately skeletonized, but maintained a nearly half centimeter wide band of subcutaneous tissue containing the corresponding veins. The flap was tunneled under the skin bridge in to the defect in a single stage procedure (Case 1) [Figure 1-6].

Hard palatal muco-periosteal free graft, lining the islanded flap provided the inner lamella to the lower eyelid defect. Continuous inverted sutures were used to anchor this graft to the outer lamella (Case 2) [Figure 7-12].

\section{DISCUSSION}

Full thickness reconstruction of more than half of either eyelid is a surgical challenge. Such a reconstruction requires functional as well as aesthetic considerations to be successful in the long term. Skin, mucosa, and a semi-rigid support are essential to prevent development of an ectropion.

A number of techniques combining these elements are described in the literature, with reconstruction in one or more stages. Lower lid defects were earlier repaired by advancement flaps or techniques like Tenzel's semicircular flap, reverse Cutler - Beard or the Hughes procedure.
A hard palatal muco-periosteal graft was added to line the conjunctival side of the flap to make a one-stage reconstruction of the full-thickness eyelid. A scaffold of free muco-periosteum serves as a replacement for the posterior lamella in the reconstruction of large defects involving the lower lid is the ideal substitute. The donor site morbidity is negligible.

Although the tarso-conjunctival flap is the treatment of choice in lower lid defects, the technique we describe is especially useful in cases in which it is best not to cover the eye for an extended period, and in cases involving defects extending beyond the lower lid.

The superficial temporal artery island flap is a reliable way of reconstructing the lower lid in cases where the local flaps have been used in earlier surgeries. Because of the risk of bulging, as well as for functional reasons, it is not recommended for upper eyelid reconstructions.

Satisfactory oncological, functional and aesthetic results, which represent an inseparable triad in reconstructive eyelid surgery, have been achieved by the use of the combination of a free muco-periosteal graft with an islanded skin flap for the reconstruction of the lower eyelid.

\section{RESULTS}

All grafts settled completely without resorption along with the surrounding conjunctiva between 2 and 3 weeks. The functional and aesthetic results have been acceptable in all the three cases.

Aesthetic and functional results of the donor and recipient area were good.

The versatility of the islanded forehead flap along with the muco-periosteal graft allows it to be successfully used for reconstruction for the full thickness defects of the lower eyelid.

The last follow-up was satisfactory in terms of the eventual oncological, functional and aesthetic aspects.

\section{CONCLUSIONS}

Muco-periosteal free graft along with an appropriately designed island flap based on the anterior branch of the superficial temporal artery provides for a simple, single- 


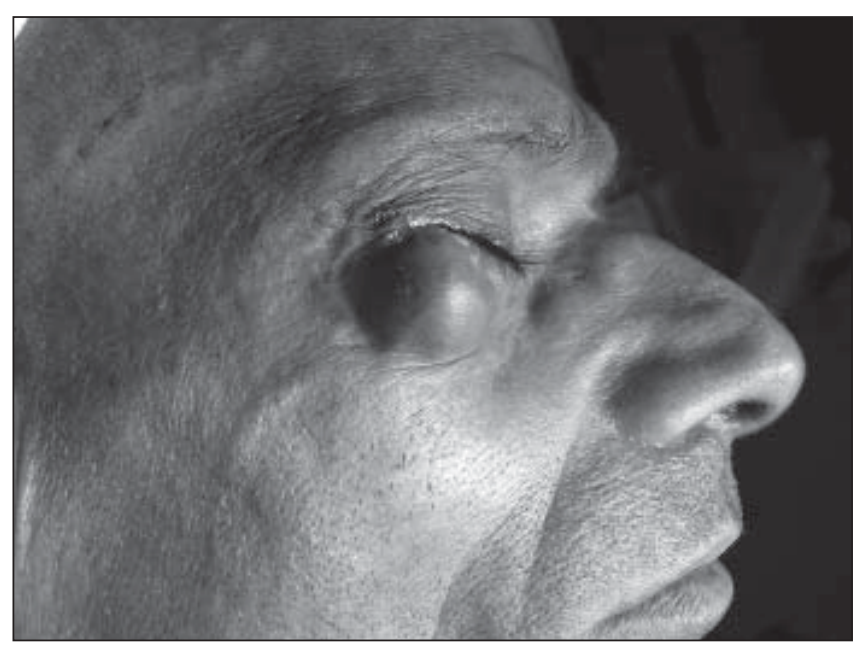

Figure 1: Lower Eyelid Tumor

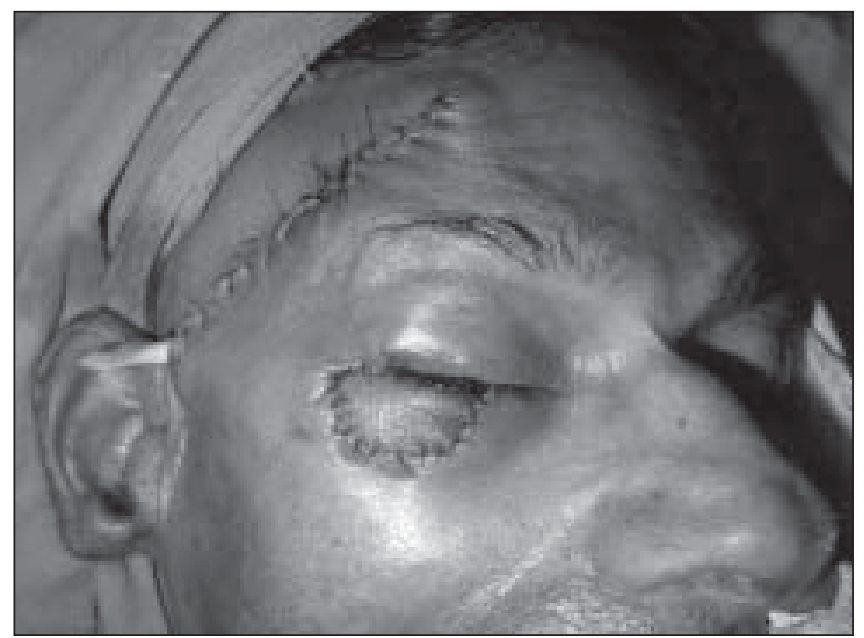

Figure 3: Skin Flap Sutured and Donor Area Closed

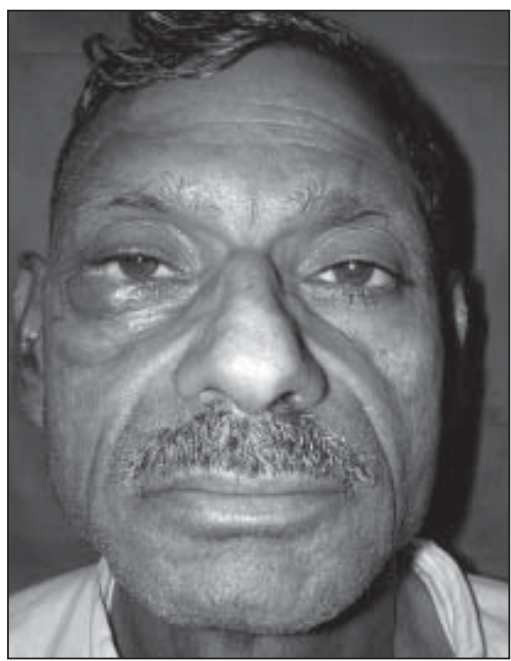

Figure 5: Final Aesthetic Result with Eyes Open

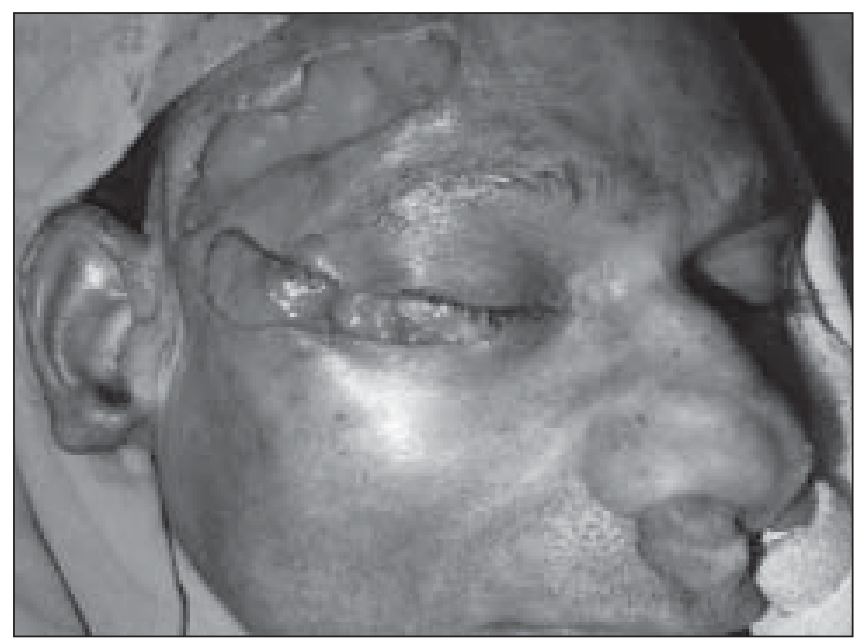

Figure 2: Tumor Excised, Palatal Mucosal Graft sutured in situ, Islanded Superficial Temporal Artery Flap Raised and Tunneled.

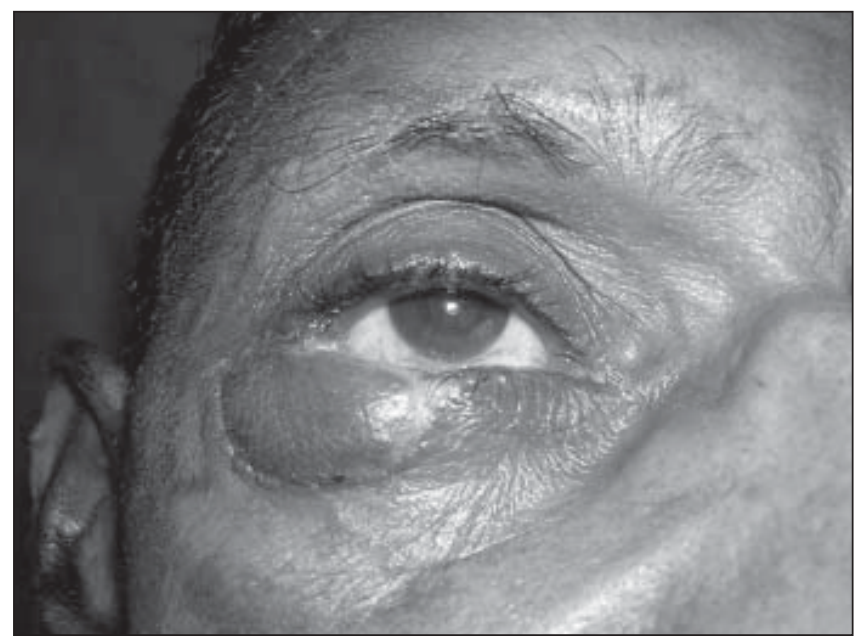

Figure 4: Follow Up After 6 Weeks

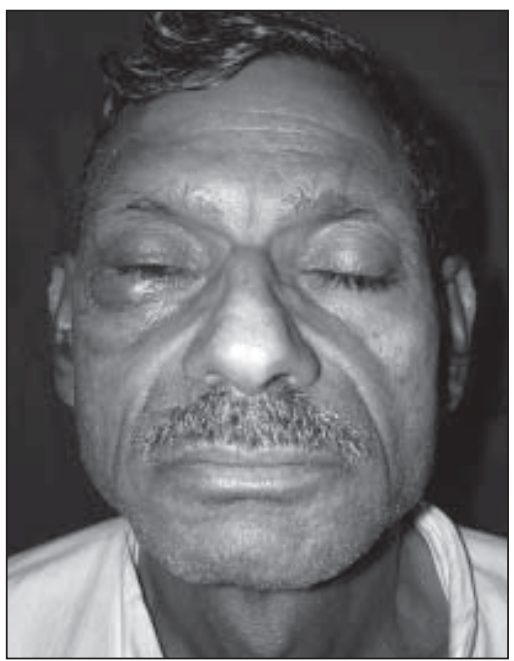

Figure 6: Final Aesthetic Result with Eyes Closed 
Jacob V, et al.

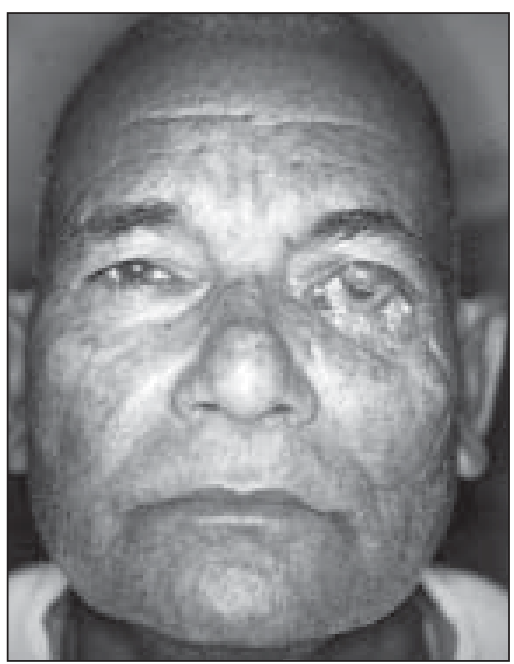

Figure 7: Lower eyelid defect at initial presentation. Note the failed upper eyelid flap lying detached from its inset

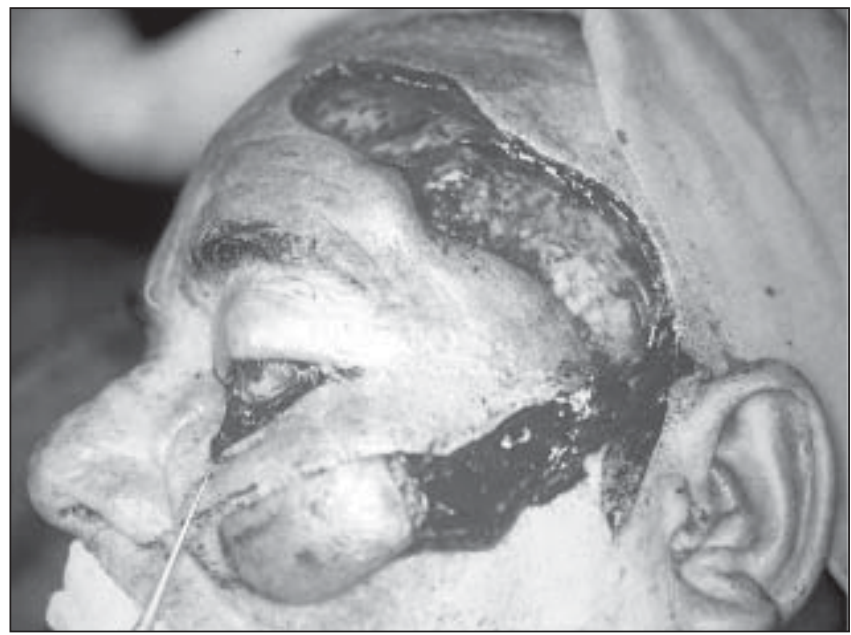

Figure 9: Flap raised (with pedicle) and the defect

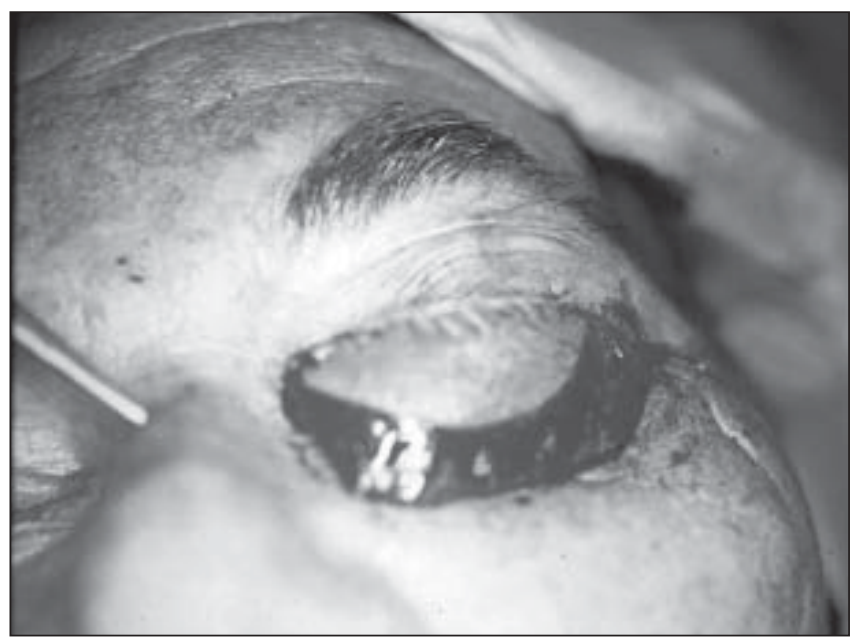

Figure 11: Final inset of flap

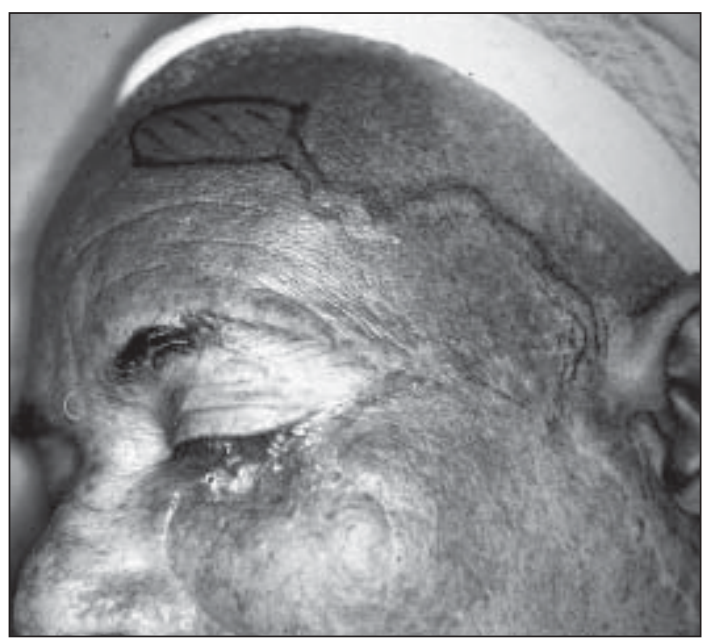

Figure 8: Flap marking on upper outer forehead, close to hairline. STA delineated by doppler/palpation

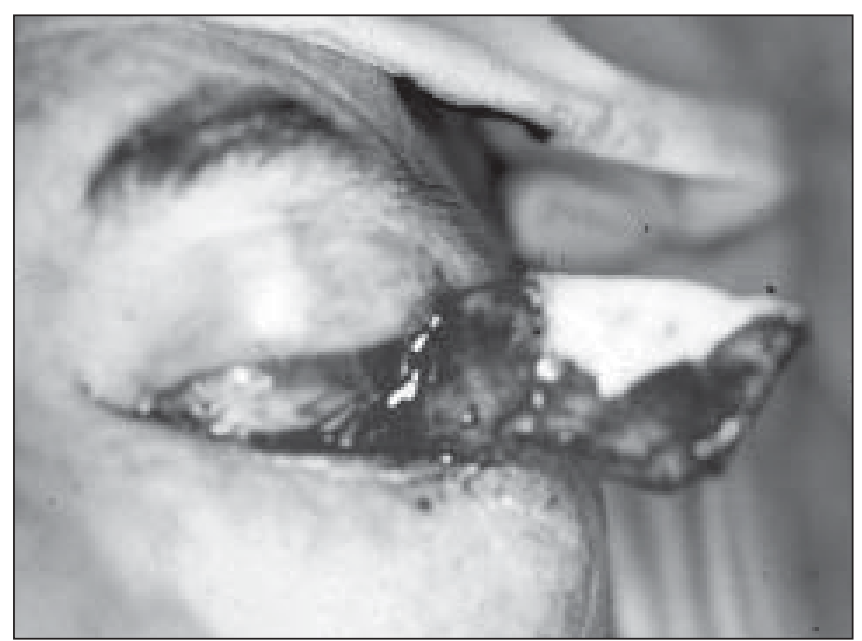

Figure 10: Flap lined on inner surface with hard palatal muco-periosteal graft

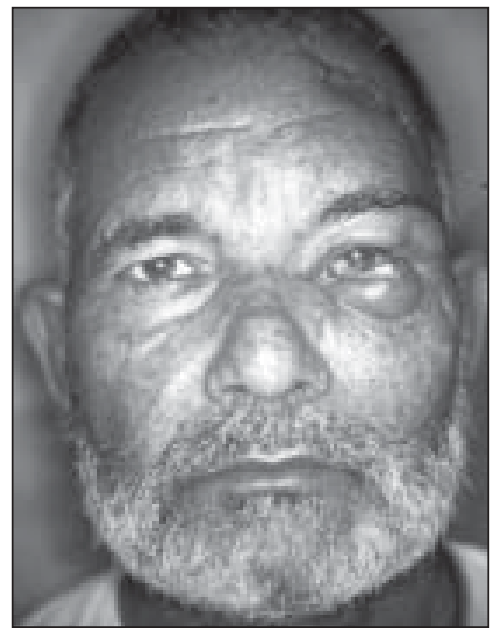

Figure 12: Final result with eyes open 
stage reconstruction option for the lower and upper eyelid.

The muco-periosteum substitutes for the conjunctiva and tarsal plate in the early postoperative period and assists epithelialization. Palatal muco-periosteum provides an abundant supply of tissue, replete with secretory elements that may be used successfully in the reconstruction of the lower eyelid. It functions as a mucosal lining in addition to a semi-rigid supporting framework.

This flap, along with full thickness muco-periosteal grafts, should be considered as first choice technique in complex, full thickness eyelid reconstruction and a possible alternative in lower eyelid reconstruction for wide defects.

\section{REFERENCES}

1. Ambrozova J, Mestak J, Smutkova J. Reconstruction of the lower eyelid after excision of major tumours. Acta Chir Plast 1993;35:131-45.

2. Anderson RL, Weinstein GS. Full-thickness bipedicle flap for total lower eyelid reconstruction. Arch Ophthalmol 1987:105:570-6.

3. Bajaj MS, Sethi A. Complicated eyelid reconstruction after an unusual glabellar flap repair. Acta Ophthalmol Scand 2000;78:599600.

4. Bakhach J, Riahi R, Demiri E, Conde A, Baudet J. The reverse auricular flap. A new flap. Ann Chir Plast Esthet 1999;44:253-61.

5. Birt BD, Antonyshyn O, Gruss JS. The temporalis muscle flap for head and neck reconstruction. J Otolaryngol 1987;16:179-84.

6. Bodian M. Extensive lid reconstruction using an augmented pedicle flap. Ann Ophthalmol. 1983;15:35-7. Clin Plast Surg. 2002;29:523-32.

7. Delay E, Lucas R, Jorquera F, Payement G, Foyatier JL. Composite cervicofacial flap for reconstruction of complex cheek defects. Ann Plast Surg. 1999 Oct;43(4):347-53. Dermatol Surg. 1997;23:395-7; 397-8.

8. Ducours JL, Failloux A, Ardanza B, Modschiedler T, Caix P. The value of a previously expanded musculo-cutaneous flap of the lower eyelid for the reconstruction of a full thickness loss of tissue substance of the upper eyelid. Rev Stomatol Chir Maxillofac 1992;93:40-5.

9. Ellis DS, Toth BA, Stewart WB. Temporoparietal fascial flap for orbital and eyelid reconstruction. Plast Reconstr Surg. 1992;89:606-12.

10. Eusterholz T, Wenzel M. Eyelid reconstruction with tarsomarginal transplant. Ophthalmologe. 1997;94:745-50.

11. Fuertes-Lanzuela S. Aesthetic total lower eyelid reconstruction. Aesthetic Plast Surg. 1988;12:159-63.
12. Furnas DW, Furnas $\mathrm{H}$. Angular artery flap for total reconstruction of the lower eyelid. Ann Plast Surg 1983;10:322-5.

13. Guerrissi JO, Jeandet F. Scalping forehead flap for extranasal reconstructions: total reconstruction of the lower lid. J Craniofac Surg. 2002;13:706-8.

14. Hallock GG. Reconstruction of a lower eyelid defect using the temporalis muscle. Ann Plast Surg. 1984;13:157-62.

15. Harma M, Asko-Seljavaara S. Temporal artery island flap in reconstruction of the eyelid. Scand J Plast Reconstr Surg Hand Surg. 1995;29:239-44.

16. Hatoko M, Kuwahara M, Shiba A, Tanaka A, Tada H, Okazaki T, et al. Reconstruction of full-thickness lower eyelid defects using a blepharoplasty technique with a hard palate mucosal graft. Ann Plast Surg 1999;42:688-92.

17. Hawes MJ. Free autogenous grafts in eyelid tarsoconjunctival reconstruction. Ophthalmic Surg 1987;18:37-41.

18. Heywood AJ, Quaba AA. A cheek island flap for the lower eyelid. Br J Plast Surg 1991;44:183-6.

19. Hurwitz JJ, Corin SM, Tucker SM. The use of free periosteal grafts in extensive lower lid reconstruction. Ophthalmic Surg 1989;20:415-9.

20. Laxenaire A, Saihi E, Huault M, Levy J. [Eyelid sebaceous carcinoma. A case report with literature review] Ann Chir Plast Esthet 2000;45:48-57.

21. Leone CR Jr, Van Gemert JV. Lower lid reconstruction using tarsoconjunctival grafts and bipedicle skin-muscle flap. Arch Ophthalmol 1989;107:758-60.

22. Molnar JA, Yan JG, Matloub HS. A prefabricated free flap for eyelid reconstruction. J Reconstr Microsurg 1998;14:479-82,483-4.

23. Moschella F, Cordova A, Di Gregorio C. Lower eyelid reconstruction by multiple subcutaneous pedicle flaps: a new method. Br J Plast Surg 1992;45:55-8.

24. Papadopoulos O, Gamatsi I. Lower lid reconstruction with a chondromucosal alar graft and upper lid musculocutaneous flap. Ann Plast Surg 1994;33:481-5.

25. Perry MJ, Langtry J, Martin IC. Lower eyelid reconstruction using pedicled skin flap and palatal mucoperiosteum. Plast Reconstr Surg 1998;102:464-72.

26. Porfiris E, Georgiou P, Harkiolakis G, Popa CV, Sandris P, Sgouras $\mathrm{N}$. Island mucochrondrocutaneous flap for reconstruction of total loss of the lower eyelid. Plast Reconstr Surg 1997;100:104-7.

27. Posazhennikov AP. Reconstruction of the removed lower eyelid by a "pocket-flap" on two pedicles. Acta Chir Plast 1982;24:4250.

28. Sasaki K, Nozaki M, Katahira J, Kikuchi Y. A nasolabial composite free flap with buccal mucosa: reconstruction of full-thickness lower eyelid defects.

29. van der Meulen JC. The use of mucosa-lined flaps in eyelid reconstruction: a new approach. Plast Reconstr Surg 1982;70:13946.

30. Whitehouse GM, Francis IC. Eyelid reconstruction using a monopedicle flap and buccal mucosa: report of 15 cases. Aust $\mathrm{N}$ Z J Ophthalmol 1988;16:295-301. 